\title{
Malaria vectors resistance to insecticides in Benin: current trends and mechanisms involved
}

\author{
Virgile Gnanguenon ${ }^{1,2^{*}}$, Fiacre R Agossa ${ }^{1,2}$, Kefilath Badirou ${ }^{1,2}$, Renaud Govoetchan ${ }^{1,2}$, Rodrigue Anagonou ${ }^{1,2}$, \\ Fredéric Oke-Agbo ${ }^{1}$, Roseric Azondekon ${ }^{1}$, Ramziath AgbanrinYoussouf ${ }^{1,2}$, Roseline Attolou ${ }^{1,2}$, Filemon T Tokponnon ${ }^{4}$, \\ Rock Aikpon 1,2, Razaki Ossè ${ }^{1,3}$ and Martin C Akogbeto ${ }^{1,2}$
}

\begin{abstract}
Background: Insecticides are widely used to control malaria vectors and have significantly contributed to the reduction of malaria-caused mortality. In addition, the same classes of insecticides were widely introduced and used in agriculture in Benin since 1980s. These factors probably contributed to the selection of insecticide resistance in malaria vector populations reported in several localities in Benin. This insecticide resistance represents a threat to vector control tool and should be monitored. The present study reveals observed insecticide resistance trends in Benin to help for a better management of insecticide resistance.

Methods: Mosquito larvae were collected in eight sites and reared in laboratory. Bioassays were conducted on the adult mosquitoes upon the four types of insecticide currently used in public health in Benin. Knock-down resistance, insensitive acetylcholinesterase-1 resistance, and metabolic resistance analysis were performed in the mosquito populations based on molecular and biochemical analysis. The data were mapped using Geographical Information Systems (GIS) with Arcgis software.

Results: Mortalities observed with Deltamethrin (pyrethroid class) were less than 90\% in 5 locations, between 90-97\% in 2 locations, and over 98\% in one location. Bendiocarb (carbamate class) showed mortalities ranged 90-97\% in 2 locations and were over $98 \%$ in the others locations. A complete susceptibility to Pirimiphos methyl and Fenitrothion (organophosphate class) was observed in all locations with 98-100\% mortalities. Knock-down resistance frequencies were high (0.78-0.96) and similar between Anopheles coluzzii, Anopheles gambiae, Anopheles arabiensis, and Anopheles melas. Insensitive acetylcholinesterase-1 was rare (0.002-0.1) and only detected in Anopheles gambiae in concomitance with Knock-down resistance mutation. The maps showed a large distribution of Deltamethrin resistance, Knock-down mutation and metabolic resistance throughout the country, a suspected resistance to Bendiocarb and detection of insensitive acetylcholinesterase- 1 from northern Benin, and a wide distribution of susceptible vectors to Pirimiphos methyl and Fenitrothion.

Conclusion: This study showed a widespread resistance of malaria vectors to pyrethroid previously located in southern Benin, an early emergence of carbamates resistance from northern Benin and a full susceptibility to organophosphates. Several resistance mechanisms were detected in vectors with a potential cross resistance to pyrethroids through Knock-down and metabolic resistance mechanisms.
\end{abstract}

Keywords: Pyrethroids resistance, Bendiocarb resistance, Insensitive acetylcholinesterase-1, Knock-down resistance, Resistance map

\footnotetext{
* Correspondence: amerusangel@yahoo.fr

${ }^{1}$ Centre de Recherche Entomologique de Cotonou (CREC), Cotonou, Benin

${ }^{2}$ Faculté des Sciences et Techniques de l'Université d'Abomey-Calavi,

Abomey-Calavi, Benin

Full list of author information is available at the end of the article
} 


\section{Background}

For malaria vector control intervention, Indoor Residual Spray and Insecticide Treated Net are so far the most effective tools used [1-3]. These two interventions are based on the use of different classes of insecticide.

Pyrethroid insecticides are considered most suitable for mosquito nets treatment due to their high insecticidal potency at low dosages and a relative safety for human contact and domestic handling [2]. They included: Lambdacyhalothrin, Permethrinn, Alpha-cypermethrin, Etofenprox, and Cylfluthrin [2]. They have a quick knock-down and lethal effect on Anopheles gambiae sensu lato (An. gambiae s.l) mosquitoes at low concentrations [3]. The majority of longlasting insecticide-treated nets freely distributed in all localities in Benin through mass-distribution campaigns and routine distributions since 2007 were Deltamethrin and Permethrin based [4-6].

Bendiocarb was previously used for indoor residual spray in Oueme province in Benin from 2008 to 2010 (6 spray cycles) and showed a significant reduction in malaria transmission $[7,8]$. It is also used for indoor residual spray in Atacora province each year with one spray cycle per year since 2011 [9].

But the use of these vector control tools cannot be efficient if their use does not take into account the environmental factors associated with insecticide resistance before their implementation. Pyrethroids resistance was reported in several localities in southern Benin since 1999 [10-13] and represented also a threat for these interventions. In addition, the lack of baseline data before the implementation of vectors control intervention in an area needs to be addressed. For example, the National Malaria Control Program (NMCP) needs data on the dynamics of insecticide resistance in all the epidemiological patterns of the country, particularly a map on the entomological situation of Benin, to be used as a guide to the choice of vector control strategies. This study was developed in this framework. The study was conducted in eight randomly selected sites. The eight sites were selected in the main malaria eco-epidemiological areas of Benin where geography (climate, land, vegetation and agriculture practices) and malaria prevalence were different [14]. At each site, the level of vector resistance (Pyrethroids, Carbamates, and Organophosphates) and the resistance mechanisms (Kdr-west, Ace- $1^{\mathrm{R}}$ and metabolic resistance) involved were assessed. A mapping of the distribution of vector resistance and vector resistance mechanisms was done. Data gathered in the different malaria eco-epidemiological areas will guide malaria vectors resistance strategies in Benin.

\section{Methods}

\section{Study design}

The study was conducted in each rainy season (AprilJuly; October-November) in 2012, 2013, and 2014 in eight districts randomly selected from different geoepidemiological regions in Benin [14]. The selected districts were:

- Adjohoun, Allada, Pobe, and Ouidah in wet savanna and degraded forest regions, southern Benin [15-18];

- Kandi and Malanville in dry savanna region, northern Benin [19,20];

- Dassa in the central part, and Parakou in the north southern part, are located between the dry and wet savanna region (transition zone) [21,22].

Atacora region, where indoor residual spray was ongoing, was excluded due to the specific vector resistance monitoring system implemented in this area, that was well documented $[9,23]$.

Anopheles gambiae s.l larvae were collected based on dipping method in four villages randomly selected in each district, then bred to adult phase (They were pooled together to have sufficient adult of the same physiological age by district) and tested with different classes of insecticides (with around 150 mosquitoes tested/insecticide/location) using WHO susceptibility (tube/cylinder) tests guidelines [14]. Mosquitoes tested were subjected to specific polymerase chain reaction treatments for species identification, and determination of resistance mechanism (Kdr-west and Ace- $1^{\mathrm{R}}$ ). Geographic information system was then used to show the distribution of phenotypic and genotypic resistances with Arcgis 10.1 software.

\section{Study areas}

\section{Adjohoun}

Adjohoun (6 $6^{\circ} 43^{\prime} 12.76^{\prime \prime} \mathrm{N}$ and $\left.2^{\circ} 29^{\prime} 19.68^{\prime \prime} \mathrm{E}\right)$ is located in the center of Oueme County. It is under a subtropical climate with two rainy seasons (a long rainy season from April to July and a short one from September to November) and two dry seasons (a long dry season from December to March and a short from September to August). The annual average rainfall is $1122 \mathrm{~mm}$ [18] (Figure 1).

\section{Allada}

Allada $\left(6^{\circ} 44^{\prime} 37.01^{\prime \prime} \mathrm{N}\right.$ and $\left.2^{\circ} 8^{\prime} 13.32^{\prime \prime} \mathrm{E}\right)$ is located in the north of Atlantique County. The climate is subequatorial with two rainy seasons and two dry seasons similar to those of Adjohoun. The annual average rainfall is about $800-1100 \mathrm{~mm}$ [16] (Figure 1).

\section{Pobe}

Pobe $\left(7^{\circ} 49^{\prime} 58.83^{\prime \prime} \mathrm{N}\right.$ and $\left.2^{\circ} 13^{\prime} 37.60^{\prime \prime} \mathrm{E}\right)$ located in southeastern Benin in Plateau County and have a boundary with Nigeria. The climate is sub-equatorial with the same two rainy seasons and two dry seasons 


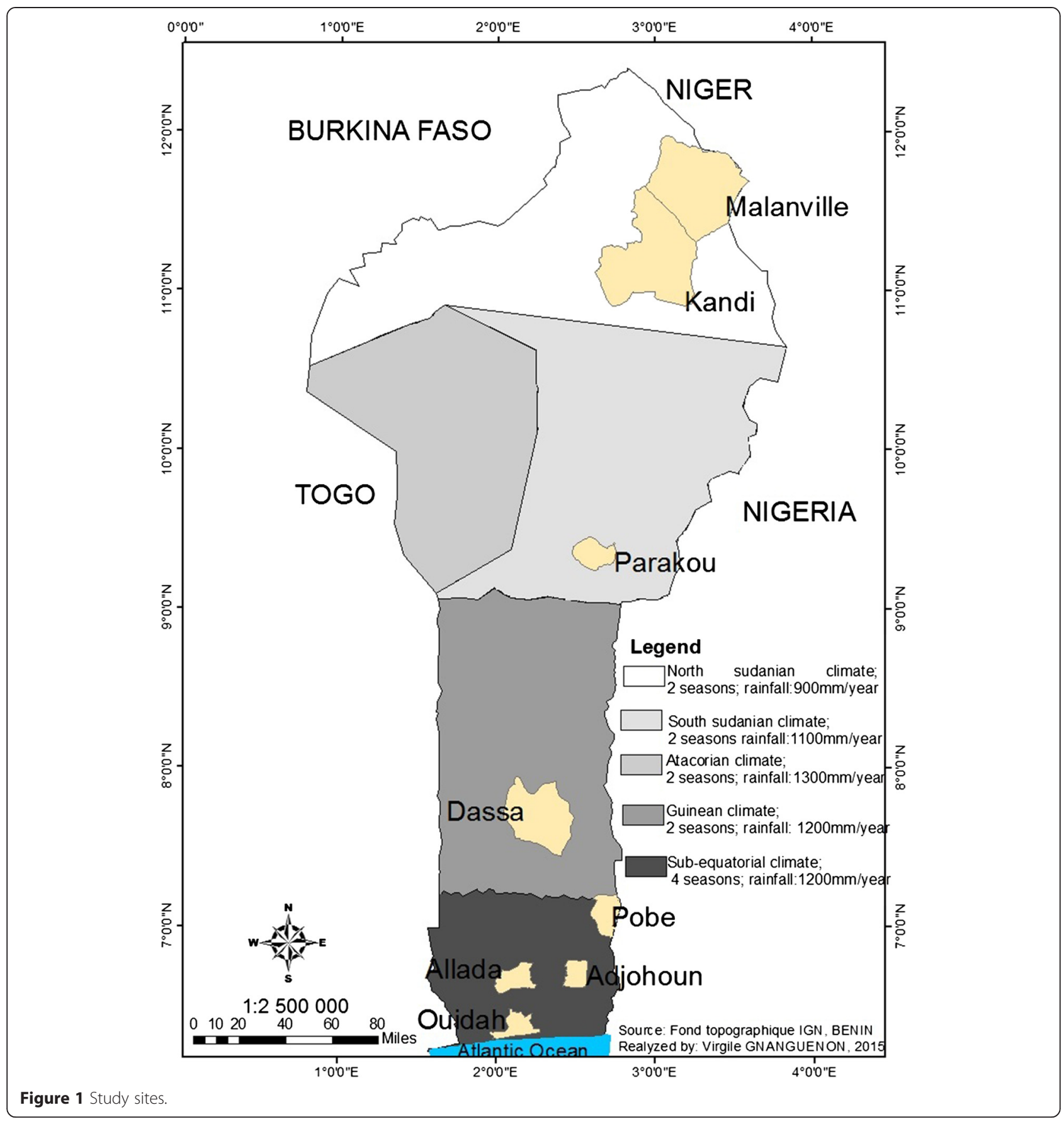

as above (characteristics of south Benin). The rainfall varies from 1100-1200 mm per year [17] (Figure 1).

\section{Ouidah}

Ouidah $\left(6^{\circ} 19^{\prime} 14.48^{\prime \prime} \mathrm{N}\right.$ and $\left.2^{\circ} 4^{\prime} 0.25^{\prime \prime} \mathrm{E}\right)$ belongs to a geographic area called "wet zone". The climate is subequatorial, characterized by two rainy seasons and two dry seasons. The rainfall varies from $950-1150 \mathrm{~mm}$ per year [15] (Figure 1).

\section{Dassa}

Dassa-Zoume $\left(7^{\circ} 49^{\prime} 58.83^{\prime \prime} \mathrm{N}\right.$ and $\left.2^{\circ} 13^{\prime} 37.60^{\prime \prime} \mathrm{E}\right)$ is one of the six districts in Collines County. The climate is Guinean with two rainy seasons and two dry seasons. The highest rainfall is recorded between July and September. The average rainfall is around $1100 \mathrm{~mm}$ [21] (Figure 1).

\section{Parakou}

Regional capital of northern Benin, Parakou ( $7^{\circ} 49^{\prime} 58.83^{\prime \prime} \mathrm{N}$ and $\left.2^{\circ} 13^{\prime} 37.60^{\prime \prime} \mathrm{E}\right)$ is located in Borgou County. The 
climate is South Sudanian-characterized by a rainy season (May to October) and a dry season (November-April). The average annual rainfall is $1200 \mathrm{~mm}$. The maximum occurs from July to September [22] (Figure 1).

\section{Kandi}

Kandi $\left(11^{\circ} 4^{\prime} 58.91^{\prime \prime} \mathrm{N}\right.$ and $\left.2^{\circ} 13^{\prime} 37.60^{\prime \prime} \mathrm{E}\right)$ is located in the center of Alibori County. The climate is North Sudanian characterized by two distinct seasons: a rainy season from April to October and a dry season from November to March. The annual average rainfall varies considerably between 700 and $1400 \mathrm{~mm}$ [19] (Figure 1).

\section{Malanville}

Malanville ( $11^{\circ} 48^{\prime} 49.06^{\prime \prime} \mathrm{N}$ and $\left.3^{\circ} 22^{\prime} 58.08^{\prime \prime} \mathrm{E}\right)$ is located in the extreme north of Benin in Alibori County. The climate of Malanville is North Sudanian. The average rainfall turns around $750 \mathrm{~mm}$ [20] (Figure 1).

\section{Mosquito collections}

Anopheles gambiae sensu lato larvae and pupae were collected from natural breeding sites of each district. Mosquito larvae and pupae collected were kept in separated labeled bottles related to each district, transported to the insectaria and maintained at a relative humidity of $72 \pm 5 \%$ and a temperature of $28 \pm 2^{\circ} \mathrm{C}$. An. gambiae s.l larvae were identified and separated for rearing. Adults were provided with $10 \%$ sugar solution. Unfed $A n$. gambiae s.l adults, female aged from 2 to 5 days from each district were pooled together to have a sizable mosquito sample $(\mathrm{n}=150)$.

\section{Insecticide susceptibility tests}

Mosquitoes were assessed using World Health Organization discriminating dosages with four insecticides: $0.1 \%$ Deltamethrin, $0.1 \%$ Bendiocarb, $0.25 \%$ Pirimiphos méthyl, and 1\% Fenitrothion. 20-25 unfed females were exposed to the diagnostic doses of insecticide treated papers for $60 \mathrm{~min}$ at $27 \pm 1^{\circ} \mathrm{C}$ and $80 \%$ relative humidity. Exposed mosquitoes were introduced into each tube and inspected at different time intervals $(10,15,20,30,45,60$ minutes), 'Immediate mortality' (0.1\% Bendiocarb, $0.25 \%$ Pirimiphos méthyl, and 1\% Fenitrothion) and "knocked-down" (for 0.1\% Deltamethrin) were recorded. After exposure, mosquitoes were kept in observation tubes and provided with a $10 \%$ honey solution. Mosquitoes exposed to untreated papers were used as control. Mortalities were recorded after 24 hours and susceptibility status of mosquito populations was graded according to the World Health Organization protocol [24]. Dead and surviving mosquitoes from assessments were used for molecular analysis.
Species identification and PCR detection of Knock-down resistance (Kdr) and insensitive acetylcholinesterase-1 $\left(\right.$ Ace- $\left.{ }^{\mathrm{R}}\right)$ mutations

Around 48 mosquitoes by site were randomly selected from live and dead mosquitoes and subjected to Polymerase Chain Reaction (PCR) for species identification [25]. DNA extracted from specimens of Anopheles gambiae sensu stricto were subjected to PCR for identification of 'Anopheles coluzzii' and 'Anopheles gambiae' [26].

The Polymerase Chain Reaction-Restriction Fragment Length Polymorphism diagnostic test was used to detect the presence of L1014F mutation ( $\mathrm{Kdr}$ ) according to the method described by Martinez-Torres et al. [27] and G119S mutation $\left(\right.$ Ace- $1^{\mathrm{R}}$ ) using the method describe by Weill et al. [28].

\section{Biochemical analysis}

Biochemical analysis was performed on 50 mosquitoes stored at $280 \mu \mathrm{C}$ within $24 \mathrm{~h}$ from emergence from each district. These mosquito samples were not exposed to any insecticides prior to biochemical assays. Levels of activity of mixed function oxidases (MFO), non-specific esterases ( $\alpha$ and $\beta$-esterases), and glutathione S-transferases (GST) were compared in susceptible An. gambiae Kisumu and the field populations from each district.

Oxydase activity was assessed using heme-peroxidase assay to identify the elevation in the amount of heme according to the method described by Brogdon et al. [29]. Non-specific esterase activity was measured using a-naphtol acetate and b-naphtol acetate and final concentrations were determined at $550 \mathrm{~nm}$ [30]. Glutathione- Stransferase (GST) activity was measured in mosquitoes using $200 \mathrm{ml}$ of GSH/CDNB working solution added to each replicate of mosquito homogenate. The kinetic reaction was read at $340 \mathrm{~nm}$ immediately for 5 minutes [30].

\section{Data analysis}

World Health Organization criteria [24] were used to determine resistance status of mosquito population as follows:

\footnotetext{
Mortality rate is $>\mathbf{9 8 \%}$ : susceptible mosquito population;

Mortality rates ranged between $90-\mathbf{9 8 \%}$ : suspected resistance in the mosquito population;

Mortality rates $<\mathbf{9 0 \%}$ : resistant mosquito population to the insecticide.
}

Knock-down and Immediate mortality were very low at 10 minutes and were then analyzed from 15 minutes. Mortality rates of An. gambiae populations were compared using Fisher's exact test. Allelic frequencies of L1014F mutation and G119S mutation were analyzed to assess variability of mutation frequencies across 
populations. Only Deltamethrin, Knock-down and Ace $-1^{R}$ resistance data were analyzed for Ouidah due to several unsuccessful mosquito larvae collections at this site.

All statistical analysis was performed using R 2.15 software.

\section{Results}

\section{Effect of Deltamethrin on mosquitoes}

The knock-down effect of Deltamethrin on mosquitoes tested was very low (Figure 2). After 15 minutes, the proportion of mosquitoes knocked-down was between 0 and $16 \%$ versus $86 \%$ for the negative control Kisumu. The effect of Deltamethrin on the different populations after 15 minutes of exposure was similar ( $p>0.05)$. The knock-down effect after 30 minutes of exposure to Deltamethrin varied from 0 to $60 \%$ but with a significantly low effect on populations of mosquitoes Parakou, Kandi and Malanville compared to other sites $(\mathrm{P}<0.05)$. At 60 minutes exposure, the knock-down effect of Deltamethrin on mosquito populations tested was less than $80 \%$ versus $100 \%$ for the susceptible strain Kisumu (control). Parakou and Malanville showed the lowest Knock-down effects (12-19\%) after an hour of exposure.

Twenty-four hours post-exposure (Figure 3), the highest mortality rate $(100 \%)$ was observed with mosquito population from Ouidah (versus 100\% for Kisumu), suggesting a full susceptibility of this population to Deltamethrin (Figure 3). A suspected resistance to Deltamethrin of mosquito populations from Pobe and Parakou was observed with respective mortalities of 91 and 97\%. In Malanville, Kandi, Dassa, Adjohoun and Allada mortalities ranged between 14 and $87 \%$, showing that vectors from these sites were resistant to Deltamethrin.

\section{Effect of Bendiocarb on mosquitoes}

After $15 \mathrm{~min}$, the immediate mortalities induced by Bendiocarb on different population of mosquitoes varied between 0 and 27\%. A significant difference was observed between the immediate mortalities induced by Bendiocarb on mosquitoes from Pobè, Kandi and Malanville and those of Parakou, Allada, Dassa and Adjohoun ( $\mathrm{p}<0.05)$. The proportion of dead mosquitoes after 30 minutes of exposure to Bendiocarb is from 3 to $93 \%$. After 60 minutes of exposure, approximately $80 \%$ of tested mosquitoes are dead except Parakou, Dassa and Adjohoun where the observed mortality is significantly lower (33-77\%) (Figure 4).

Mortality rates observed after 24 hours in Pobè, Dassa, Allada, Malanville and Adjohoun exceeded 98\% (Figure 5) versus $100 \%$ for Kisumu. At Kandi and Parakou the observed mortality rates were respectively $92.93 \%$ [86.12 to 96.53] and $89.53 \%$ [ 81.88 to 94.24]. This shows a reduced susceptibility in mosquito of Kandi and resistance in mosquito of Parakou (Figure 5). These results suggest the emergence of resistance to Bendiocarb from the north of Benin (Figure 5).

\section{Effect of Pyrimiphos methyl on mosquitoes}

The immediate mortalities induced by Pirimiphosmethyl varied significantly between different mosquito populations tested $(\mathrm{p}<0.05)$ (Figure 6). It is after thirteen minutes that the effect of Pirimiphos methyl was more perceptible on mosquitoes (Figure 6). The observed immediate mortalities range from 24-95\% in Allada, Parakou, Kandi and Malanville. But, in Pobè, Adjohoun and Allada, the majority of mosquitoes were still alive (Figure 6). After an hour of exposure, immediate mortality increased in all sites (43-100\%) except Pobè and Adjohoun where mortality is almost zero (Figure 6).

Mortalities noted after 24 hours of observation were $100 \%$ suggesting a complete susceptibility of all mosquito populations tested to Pirimiphos methyl (Figure 7).

\section{Fenitrothion effect on mosquitoes}

The effect of Fenitrothion on mosquitoes tested was low and similar between mosquito populations during exposure (Table 1). After 15 and 30 minutes of exposure, the

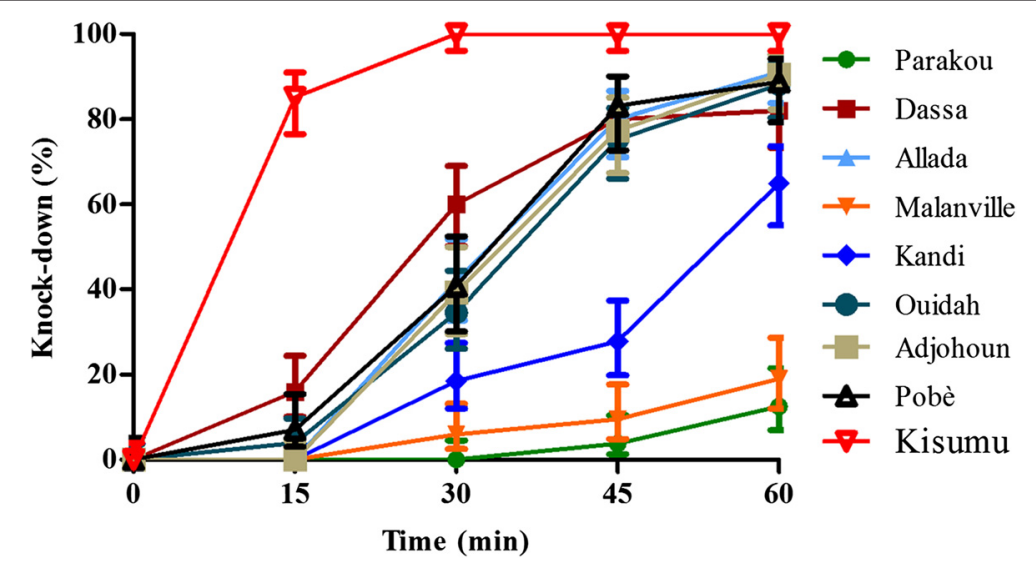

Figure 2 Knock-down rates of mosquitoes due to exposure to Deltamethrin. 


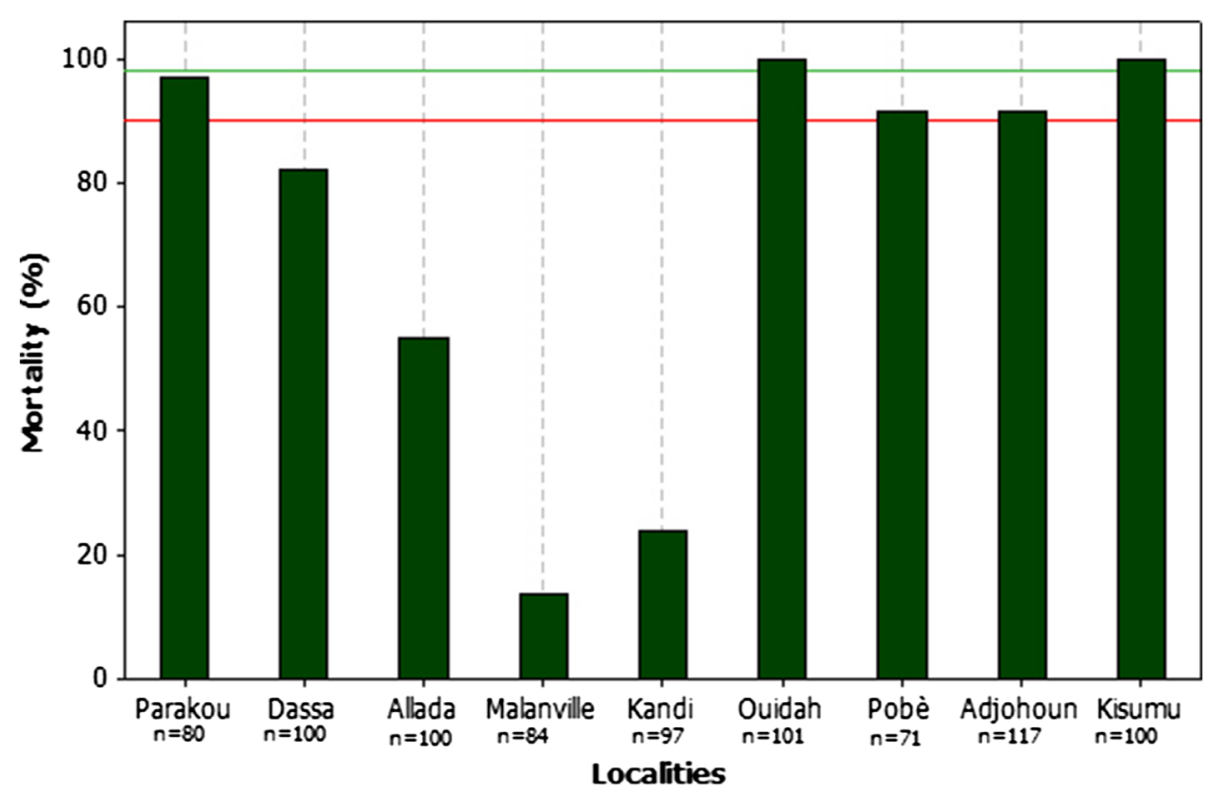

Figure 3 Observed mortalities with Deltamethrin.

observed immediate mortalities were almost null ( 0 to $2.40 \%)$. After 45 minutes, the immediate effect of Fenitrothion was more evident on mosquito population from Malanville (25.61\% [17.40 to 36.00]) and Allada (23\% [32, 15 to 15.84]) versus $100 \%$ fro Kisumu. At 60 minutes of exposure, immediate mortalities increased to $75 \%$ in Malanville, Kandi, Parakou, and Dassa Allada. But, in Pobè and Adjohoun immediate mortalities remained zero.

After 24 hours of observation, mortalities varied from 98 to $100 \%$ suggesting that all vector populations tested were susceptible to Fenitrothion (Table 1).

In summary, Deltamethrin resistance was widely distributed throughout the country (Figure 8). A suspected resistance to Bendiocarb was observed from the northern part of the country while a full susceptibility was observed in the south (Figure 8). A full susceptibility of vector populations to Pirimiphos methyl and Fenitrothion was also from south to north (Figure 8).

\section{Multiple insecticide resistance mechanisms in Anopheles gambiae}

Data presented in Table 2 shows the distribution of Knock-down resistance among $A n$. gambiae complex species (An. gambiae, An. arabiensis, An. coluzzi, and An. melas). An. gambiae, An. arabiensis, and An. coluzzi were identified at Allada, Dassa, Parakou, Malanville, and Kandi but at Ouidah, $A n$. melas was found instead of $A n$. arabiensis (Table 2). Knock-down resistance frequencies were high (78-93\%) in all species and at all sites. No significant difference was observed when comparing Kdr freaquency between An. gambiae, An. Arabiensis, An. coluzzi,

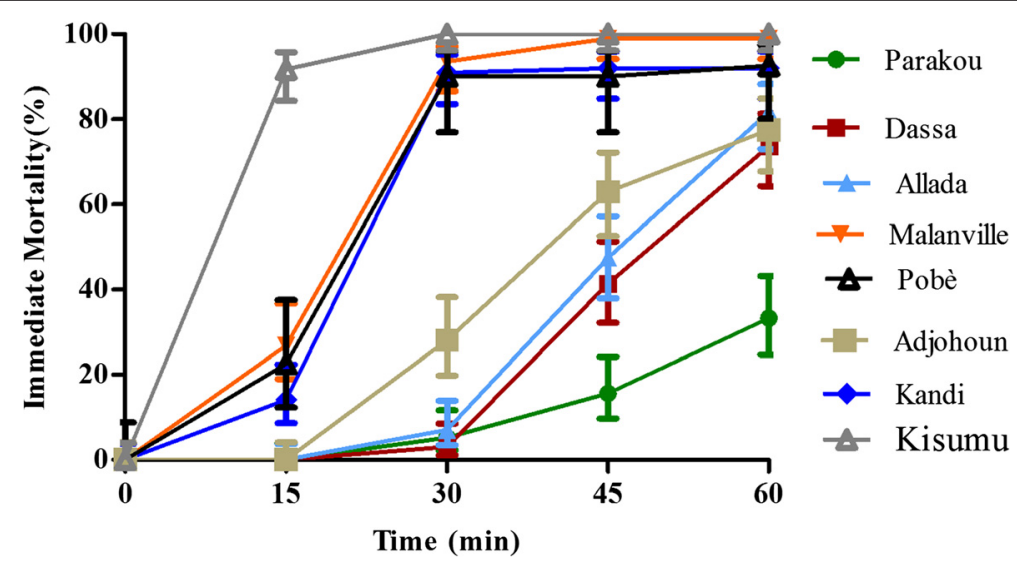

Figure 4 Immediate mortalities observed during mosquitoes exposure to Bendiocarb. 


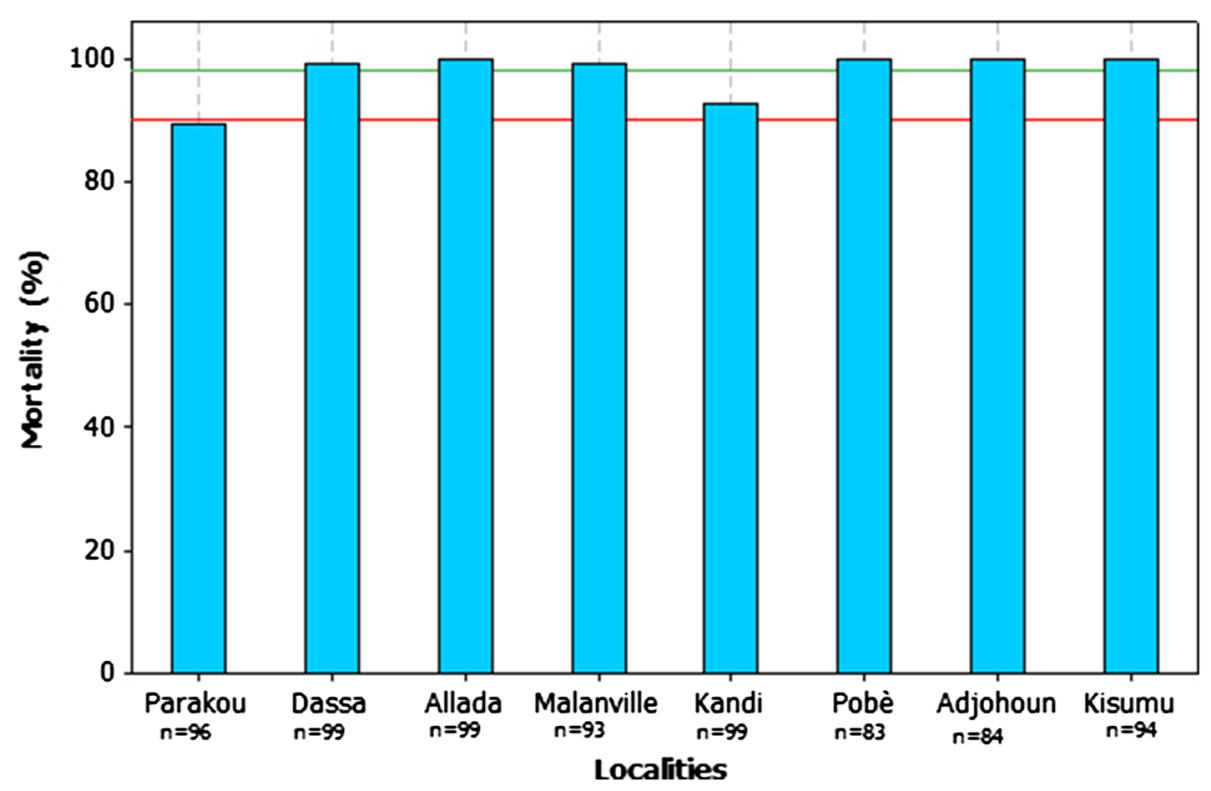

Figure 5 Observed mortalities with Bendiocarb.

and An. melas ( $\mathrm{p}>0.05$ ). RR and RS genotypes of Kdr were found in both dead and survivors but no SS was found.

Insensitive acetylcholinesterase- 1 mutation (Ace- $1^{\mathrm{R}}$ ) was also identified at Kandi and Parakou at very low frequency (1\%). At the other localities this mutation was absent with a null frequency (Table 3 ). It was not detected in An. coluzzii, An. arabiensis and An. melas species but only in heterozygous form in four surviving $A n$. gambiae species (three from Parakou and one from Kandi) that were previously identified with Knock-down resistance mutation (Table 3 ).

Biochemical assays showed significantly high enzymatic activities (MFO, NSE and GST) in some populations of mosquitoes. Figure 9 shows the average level of oxidase activity (MFO) in the different populations tested. The activity of cytochrome P450 was significantly higher in Allada Parakou compared to Kisumu $(\mathrm{p}<0.05)$ (Figure 9).

The activity of non-specific esterase ( $\alpha$ and $\beta$ esterase), was higher in mosquito populations from Kandi, Dassa Allada and Pobè compared to Kisumu $(\mathrm{p}<0.05)$ (Figures 10 and 11).

High activities of the Glutathione-S-transferase were observed in the populations of Dassa Allada and Pobè compared to Kisumu ( $<$ 0.05) (Figure 12).

The observed molecular and biochemical resistance mechanisms were mapped to show the distribution of these resistances (Figure 13).

\section{Discussion}

The present study updated data on vectors resistance to the insecticides currently used in vectors control strategies in

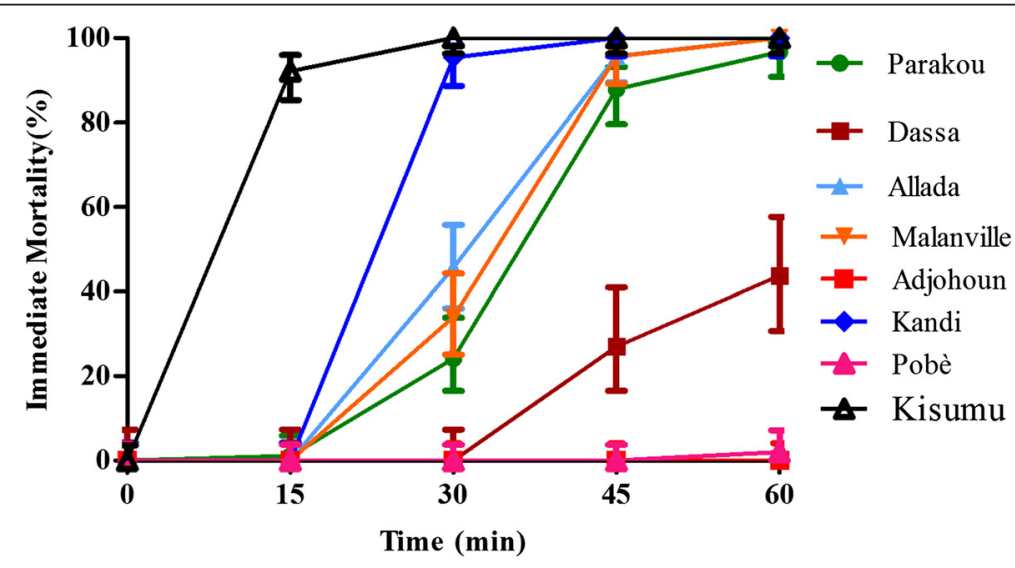

Figure 6 Immediate mortalities observed during mosquitoes exposure to Pyrimiphos methyl. 


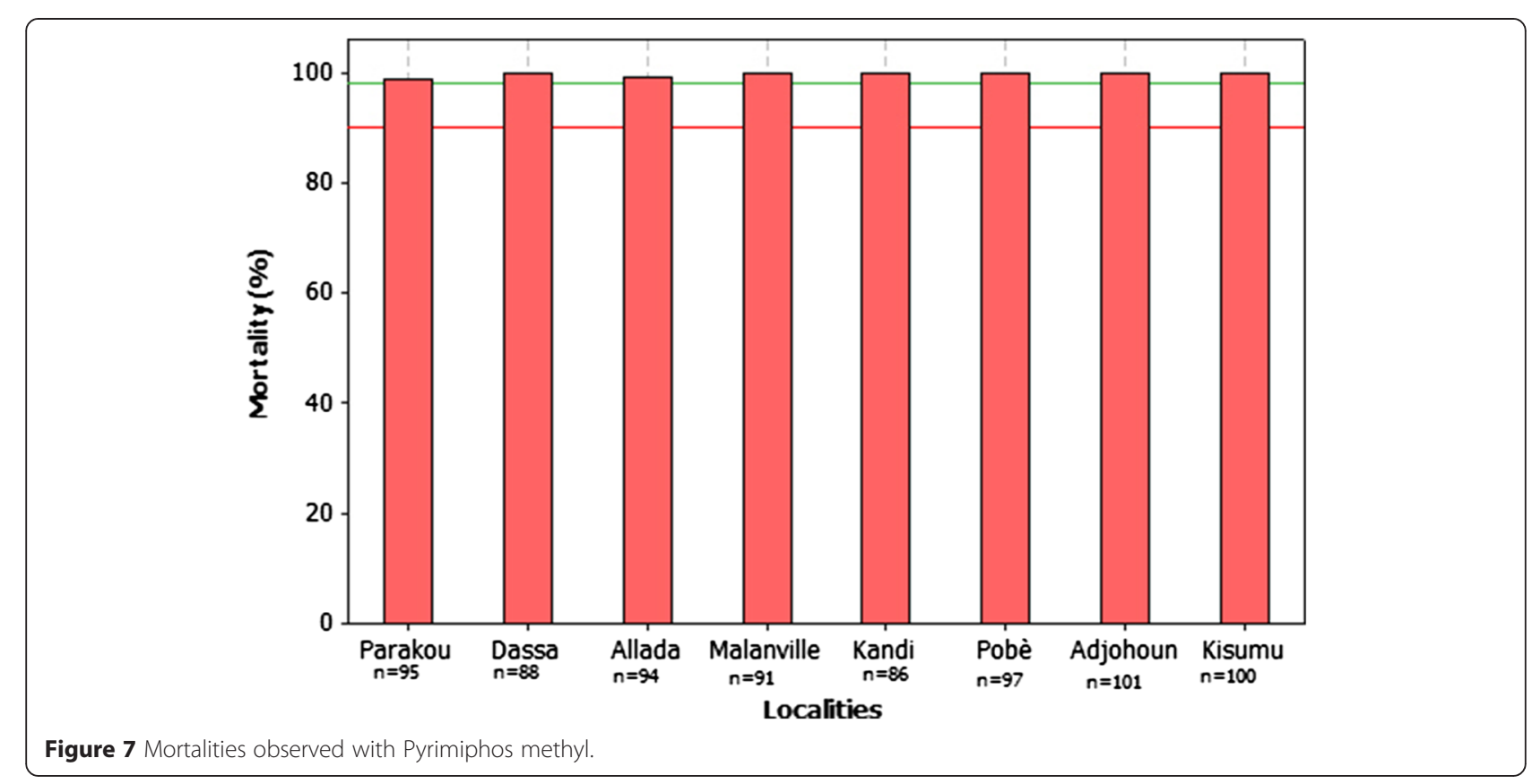

Benin and shows their distribution. It showed a confirmed resistance to Deltamethrin (pirethrinoid) throughout the country except in Ouidah, an emerging resistance to Bendiorcarb (carbamates) in northern Benin, and a full susceptibility to Pirimiphos methyl and Fenitrothion (organophosphate) with a slow effect of Fenitrothion according to WHO thresholds. These thresholds have no epidemiological meaning because the field performance of the insecticides tested remain high [31-33]. However, they were more likely designed to be the triggers of preventive action by national malaria control program to define efficient strategies to manage insecticide resistance without waiting for indisputable proof of interventions failure [24].

Resistance levels to Deltamethrin varied between localities reflecting variation in resistance selection pressures on different vector populations. Deltamethrin and Permethrin are the most found insecticides on mass-distributed insecticide-treated nets in Benin (from national campaign and routine distributions) with similar coverage rates between regions (74-94\%) [34,35]. This should select resistance in the wild mosquito populations [36] and might explain the similar frequencies of Knock-down resistance (Kdr) between regions. In addition, there are also selection pressures generated by the use of the same class of insecticide in agriculture that represent the main activities of certain districts [37-39] and could explain the observed variations. The observed resistance level to Deltamethrin observed in southern Benin was similar to the results previously reported by Djègbè et al. [13] and Sovi et al. [40].

The Knock-down resistance gene was the main resistance mechanism found in all assessed mosquito populations. It was found at very high frequencies (0.80 in average) in An. gambiae, An. coluzzii, An. arabiensis and

Table 1 Observed Knock-down rate and mortality with Fenitrothion

\begin{tabular}{|c|c|c|c|c|c|c|c|}
\hline \multirow[t]{2}{*}{ Localities } & \multirow{2}{*}{$\begin{array}{l}\text { Number } \\
\text { tested }\end{array}$} & \multicolumn{5}{|c|}{ Knock-down (\%) } & \multirow[t]{2}{*}{ Mortality (\%) } \\
\hline & & $0 \mathrm{~min}$ & $15 \mathrm{~min}$ & $30 \mathrm{~min}$ & $45 \mathrm{~min}$ & $60 \mathrm{~min}$ & \\
\hline Parakou & 86 & $0[0,00-4,28]$ & $0[0,00-4,28]$ & $0[0,00-4,28]$ & $0[0,00-4,28]$ & $24[16,56-34,46]$ & 100 \\
\hline Dassa & 99 & $0[0,00-3,74]$ & $0[0,00-3,74]$ & $1,01[0,18-5,5]$ & $3[1,04-8,53]$ & $23[16,01-32,46]$ & 100 \\
\hline Allada & 90 & $0[0,00-3,70]$ & $1[0,18-5,45]$ & $1[0,18-5,45]$ & $23[15,84-32,15]$ & $61[69,98-51,2]$ & 100 \\
\hline Malanville & 82 & $0[0,00-4,48]$ & $2[0,67-8,46]$ & $2[0,67-8,46]$ & $26[17,4-36]$ & $76[65,31-83,62]$ & 100 \\
\hline Kandi & 100 & $0[0,00-3,70]$ & $0[0,00-3,70]$ & $0[0,00-3,70]$ & $0[0,00-3,70]$ & $44[34,67-53,77]$ & 100 \\
\hline Adjohoun & 95 & $0[0,00-3,89]$ & $0[0,00-3,89]$ & $0[0,00-3,89]$ & $0[0,00-3,89]$ & $0[0,00-03,89]$ & 100 \\
\hline Pobè & 93 & $0[0,00-3,97]$ & $0[0,00-3,97]$ & $0[0,00-3,97]$ & $0[0,00-3,97]$ & $0[0,00-03,97]$ & 100 \\
\hline Kisumu & 98 & $0[0,00-3,77]$ & $82[72,83-88,05]$ & $100[96,23-100]$ & $100[96,23-100]$ & $100[96,23-100]$ & 100 \\
\hline
\end{tabular}




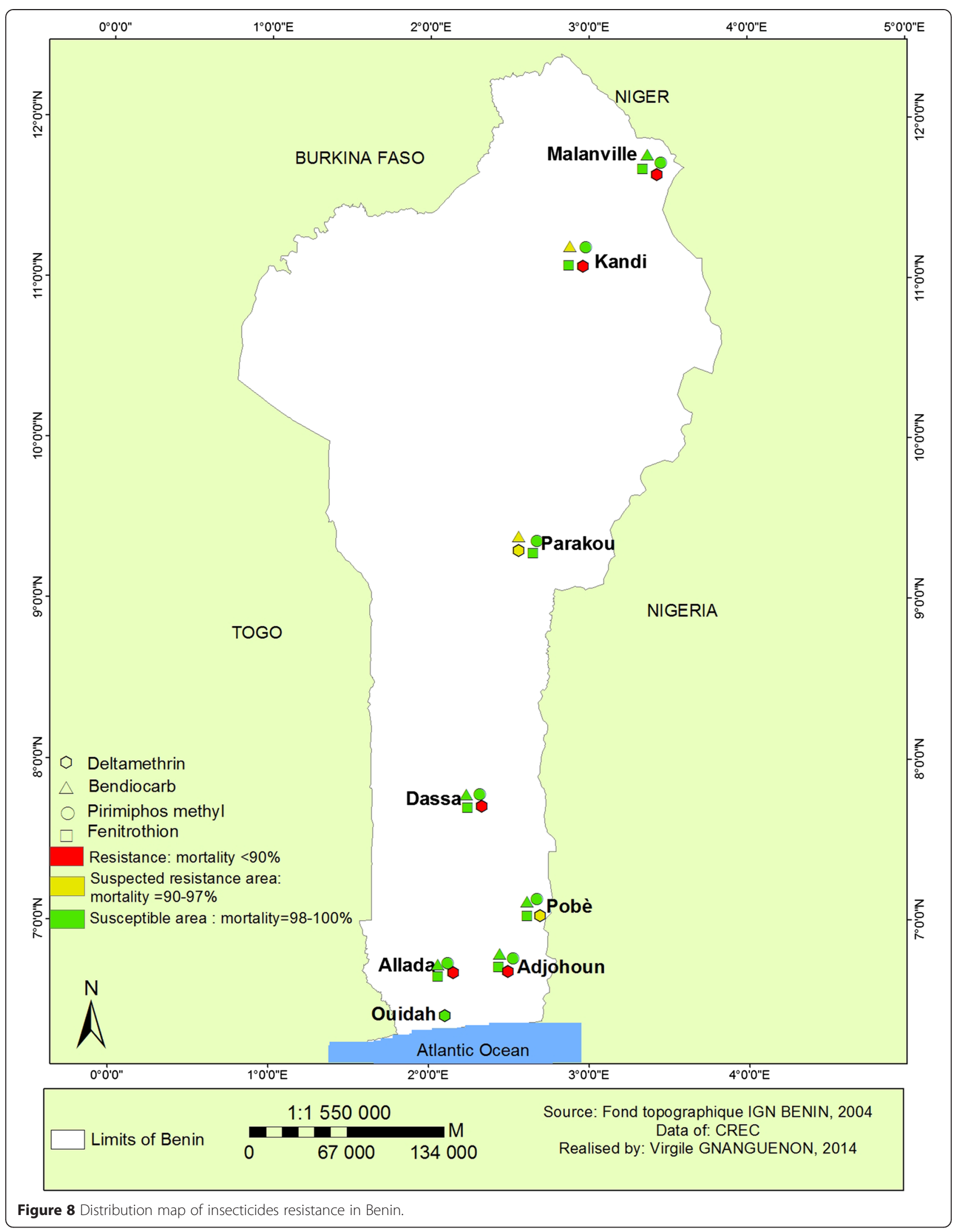


Table 2 Distribution of Knock-down resistance (Kdr) frequencies between malaria vectors and sites

\begin{tabular}{|c|c|c|c|c|c|c|c|c|}
\hline District & Species & Number & RR & RS & SS & $F(K d r)$ & OR $(95 \% \mathrm{Cl})$ & $\mathrm{p}$-value \\
\hline \multirow[t]{3}{*}{ Allada } & An. gambiae & 14 & 11 & 3 & 0 & $0,89 a$ & 1.00 & - \\
\hline & An. arabiensis & 7 & 5 & 2 & 0 & $0,86 a$ & $1.39[0.20-9.44]$ & 1.000 \\
\hline & An. coluzzi & 20 & 13 & 7 & 0 & $0,83 a$ & $1.77[0.41-7.53]$ & 0.5072 \\
\hline \multirow[t]{3}{*}{ Dassa } & An. gambiae & 21 & 17 & 4 & 0 & $0,90 a$ & 1.00 & - \\
\hline & An. arabiensis & 8 & 5 & 3 & 0 & $0,81 a$ & 2.19 [0.43-11.12] & 0.381 \\
\hline & An. coluzzi & 18 & 15 & 3 & 0 & $0,92 a$ & $0.86[0.18-4.14]$ & 1.00 \\
\hline \multirow[t]{3}{*}{ Parakou } & An. gambiae & 15 & 13 & 2 & 0 & $0,93 a$ & 1.00 & - \\
\hline & An. arabiensis & 19 & 15 & 4 & 0 & $0,89 a$ & 1.65 [0.28-9.67] & 0.6870 \\
\hline & An. coluzzi & 14 & 10 & 4 & 0 & $0,86 a$ & 2.33 [0.39-13.87] & 0.4154 \\
\hline \multirow[t]{3}{*}{ Kandi } & An. gambiae & 22 & 16 & 6 & 0 & $0,86 a$ & 1.00 & - \\
\hline & An. arabiensis & 14 & 12 & 2 & 0 & $0,93 a$ & $0.49[0.09-2.60]$ & 0.4705 \\
\hline & An. coluzzi & 12 & 11 & 1 & 0 & $0,96 a$ & $0.27[0.03-2.43]$ & 0.4073 \\
\hline \multirow[t]{3}{*}{ Malanville } & An. gambiae & 18 & 14 & 4 & 0 & $0,89 a$ & 1.00 & - \\
\hline & An. arabiensis & 3 & 2 & 1 & 0 & $0,83 a$ & $1.6[0.15-17.38]$ & 0.5568 \\
\hline & An. coluzzi & 27 & 19 & 7 & 1 & $0,83 a$ & $1.6[0.45-5.65]$ & 0.55141 \\
\hline \multirow[t]{3}{*}{ Ouidah } & An. gambiae & 9 & 5 & 4 & 0 & $0,78 a$ & 1.00 & - \\
\hline & An. melas & 27 & 19 & 8 & 0 & $0,85 a$ & $0.61[0.16-2.33]$ & 0.47922 \\
\hline & An. coluzzi & 11 & 8 & 3 & 0 & $0,86 a$ & $0.55[0.11-2.87]$ & 0.67983 \\
\hline
\end{tabular}

$\mathrm{SS}=$ homozygous susceptible; $\mathrm{RS}=$ hybrid resistant and susceptible; $\mathrm{RR}=$ homozygous resistant, $\mathrm{F}=$ Frequency.

Table 3 Distribution of Ace-1R frequency between species

\begin{tabular}{|c|c|c|c|c|c|c|c|}
\hline District & Species & Number & RR & $\mathrm{RS}$ & SS & Ace-1R & p-value \\
\hline \multirow[t]{3}{*}{ Allada } & An. gambiae & 14 & 0 & 0 & 14 & 0 & $P>0.999$ \\
\hline & An. arabiensis & 7 & 0 & 0 & 7 & 0 & \\
\hline & An. coluzzi & 20 & 0 & 0 & 20 & 0 & \\
\hline \multirow[t]{3}{*}{ Dassa } & An. gambiae & 21 & 0 & 0 & 21 & 0 & $P>0.999$ \\
\hline & An. arabiensis & 8 & 0 & 0 & 8 & 0 & \\
\hline & An. coluzzi & 18 & 0 & 0 & 18 & 0 & \\
\hline \multirow[t]{3}{*}{ Parakou } & An. gambiae & 15 & 0 & 3 & 12 & 0.1 & 0,22 \\
\hline & An. arabiensis & 19 & 0 & 0 & 19 & 0 & \\
\hline & An. coluzzi & 14 & 0 & 0 & 14 & 0 & \\
\hline \multirow[t]{3}{*}{ Kandi } & An. gambiae & 22 & 0 & 1 & 21 & 0.002 & $P>0.999$ \\
\hline & An. arabiensis & 14 & 0 & 0 & 14 & 0 & \\
\hline & An. coluzzi & 12 & 0 & 0 & 12 & 0 & \\
\hline \multirow[t]{3}{*}{ Malanville } & An. gambiae & 18 & 0 & 0 & 18 & 0 & $P>0.999$ \\
\hline & An. arabiensis & 3 & 0 & 0 & 3 & 0 & \\
\hline & An. coluzzi & 27 & 0 & 0 & 0 & 0 & \\
\hline \multirow[t]{3}{*}{ Ouidah } & An. gambiae & 9 & 0 & 0 & 9 & 0 & $P>0.999$ \\
\hline & An. melas & 27 & 0 & 0 & 27 & 0 & \\
\hline & An. coluzzi & 11 & 0 & 0 & 11 & 0 & \\
\hline
\end{tabular}

SS = homozygous susceptible; RS = hybrid resistant and susceptible; $\mathrm{RR}=$ homozygous resistant.
An. melas populations tested, and was widespread in the country. Their spread could be due to both vector bioecology and resistance selection pressure due to the intensive use of public health insecticides in agriculture [41].

In addition to pyrethroid resistance, we observed the emergence of carbamates resistance. This resistance to carbamates was previously reported in Benin by Djogbenou et al. [42] and Aïkpon et al. [9]. It was associated with very low frequency of insensitive Ace-1 gene detected. This mutation was previously reported by Corbel et al. [11], Djogbénou et al. [43], Djenontin et al. [12], Yadouléton et al. [44] and by Aikpon et al. [9]. This early spread of

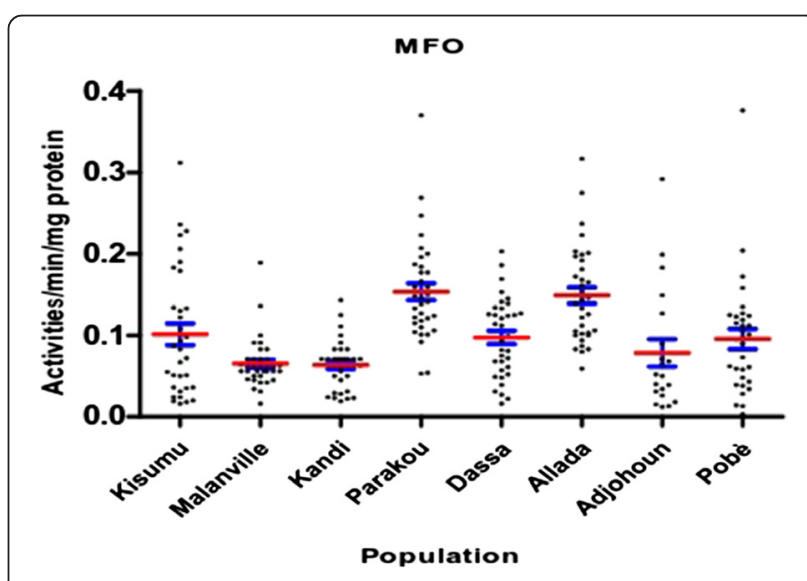

Figure 9 Mono-oxygenase activities in Anopheles gambiae sensu lato collected. 


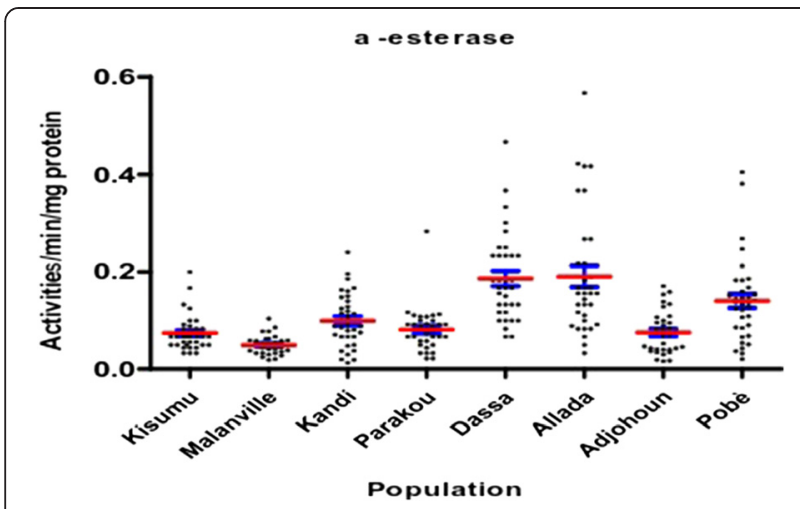

Figure $\mathbf{1 0}$ a-esterases activities in Anopheles gambiae sensu lato collected.

Ace $-1^{\mathrm{R}}$ mutation should be monitored closely. As the use of Bendiocarb in Indoor Residual Spray is part of a National Malaria Control Program strategy it could increase the frequency of the Ace $-1^{\mathrm{R}}$ gene and lead to a widespread of this resistance mutation. It is urgent for this purpose to follow-up monitoring for a better management of this resistance mechanism.

However, even if $\mathrm{Kdr}$ and Ace-1R genes confer a significant effect on vector resistance, they do not fully explain the observed vectors resistance level to insecticides because homozygous susceptible subjects (SS) survived to pyrethroids and carbamates exposure suggesting an involvement of other alternative mechanisms such as metabolic resistance mechanisms [45].

To assess the metabolic resistance mechanisms involved in the assessed vector populations, a biochemical approach was used. High activity of glutathione-s-transferase, cytochrome P450 and non-specific esterases were observed in some areas of southern and central Benin. These results were also previously reported in Atacora province [23] and in Cameroon [46]. These enzymes can confer resistance to

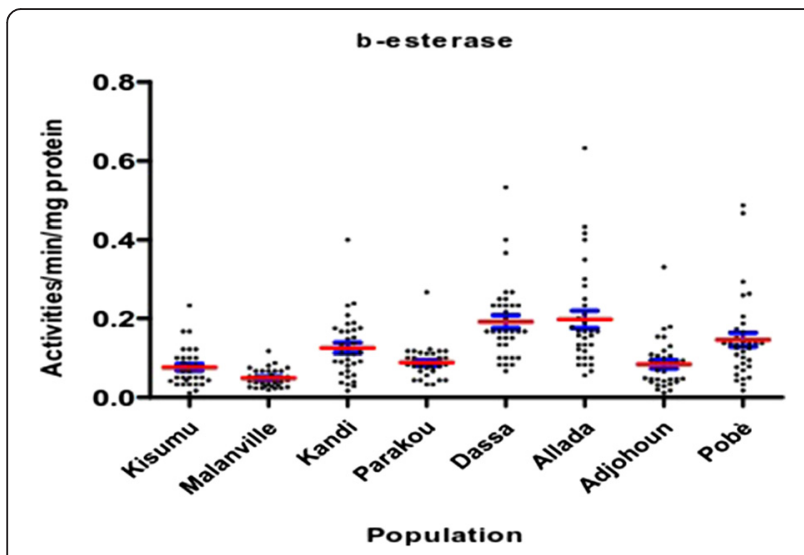

Figure $11 \beta$-esterases activities in Anopheles gambiae sensu lato collected.

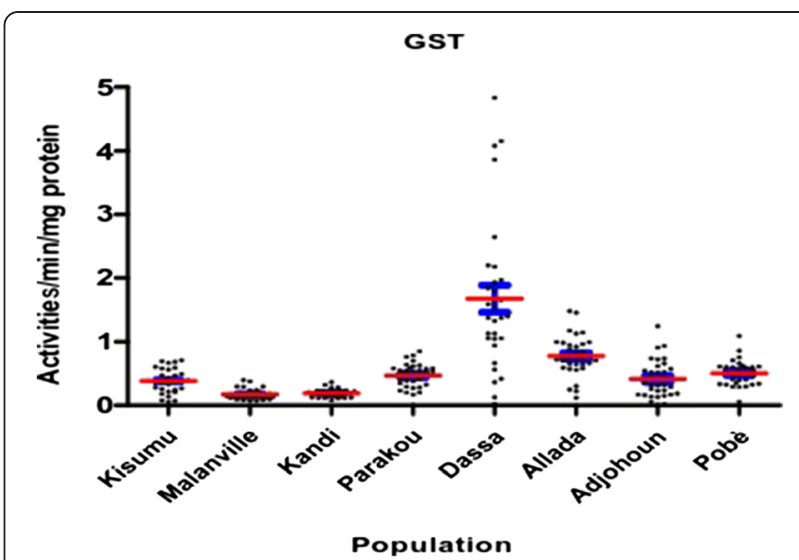

Figure 12 Glutathion-S-transferase activities in Anopheles gambiae sensu lato collected

organophosphates, organochlorines and pyrethroids [47]. They were found with $\mathrm{Kdr}$ mutation in the same vector populations and could confer a cross resistance to pyrethroids. The over expression of these enzymes could also explain the slow effect of some organophosphates like Fenitrothion on mosquito populations in absence of insensitive acetylcholinesterase-1.

Ideally, when the resistance is detected for an insecticide, other insecticide categories must be used as part of a dynamic resistance management. However, very few insecticides are currently available for treatment of mosquito nets and indoor residual spray $[48,49]$. The insecticide change can also lead to higher costs of intervention programs reducing resistance managing options. For example, the change from Bendiocarb (8 US\$/house) to Fenitrothion (15.40 US\$/house) in indoor residual spray intervention will be 2 times more expensive [50]. In general, the use of insecticides does not create resistance itself, but selects a small proportion of subjects with a genetic mutation that allow them to resist and survive the effects of the insecticide. If this advantage is maintained by a constant use of the same insecticide, the resistant insects will reproduce and the genetic changes that confer resistance are transferred from parents to offspring so that eventually resistant subjects become numerous within the population $[51,52]$. The spread of resistant subjects will take more time if the resistance gene is rare or present at low frequency. It is also complex and depends on several genetic, biological and operational factors [51]. Biological factors affect the life cycle of the insect (the reproduction rate, the number of generation or offspring, the rate of migration and isolation, etc.), while genetic factors include intrinsic characteristics of the resistance genes (mono function of polygenic resistance, domination, genetic cost and the interaction of genes) [53]. Operational factors concern the insecticide treatment itself, including the method 


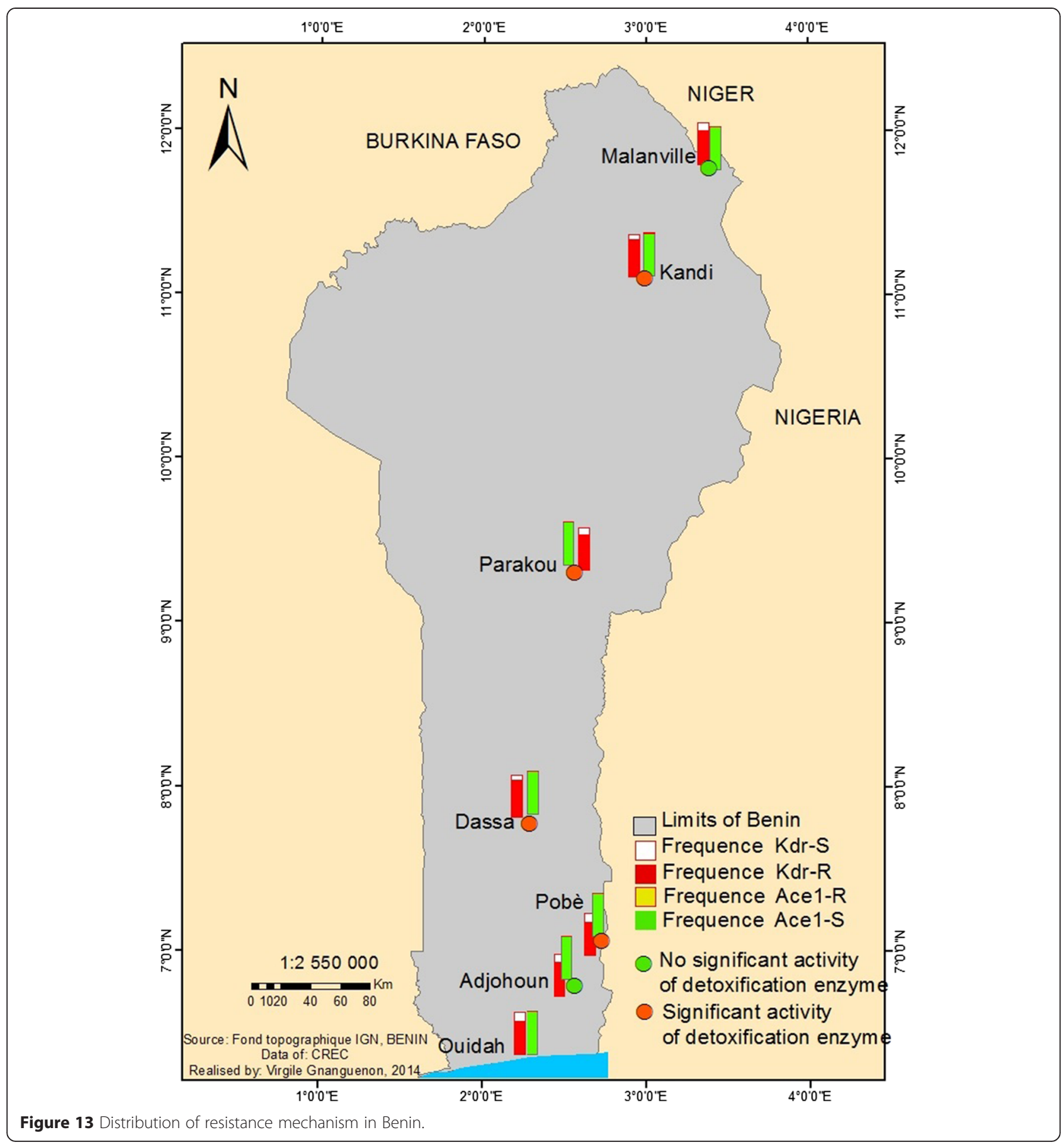

and frequency of application, dosage and the residual activity of the insecticide and the level of insecticide coverage.

In theory, the resistance management of insecticide resistance should be performed by alternating vector control methods based on the use of insecticides and non-insecticidal methods. In practice, most noninsecticidal methods work well in experimental trials but become difficult when programs intensify their long-term use (operational) [54]. Then, operationally, the simplest way of resistance management should involve insecticides management. The implementation of management strategies that may delay selection and spread of resistance to insecticides is therefore the main gateway for vector control programs. Another alternative is to find other insecticide formulations that will enhance the choice possibilities of insecticides.

This data will enable the National Malaria control programme to determine what insecticide to use and 
where. They should implement a rapid pro-active response to avoid vectors resistance to Pirimiphosmethyl and delay the spread of Bendiocarb resistance. Alternative non-insecticidal methods should be used, wherever possible, to delay insecticide resistance.

\section{Conclusion}

This study shows the resistance profile of malaria vectors to different categories of insecticides used for vector control in Benin. A widespread malaria vector resistance to pyrethroid and an early emergence of carbamates resistance in the northern region of the country were observed. However, vectors were fully susceptible to organophosphates including Pirimiphos methyl and Fenitrothion but with a rapid susceptibility to the effect of Pirimiphos methyl.

This useful information could help policy-makers to better plan insecticide resistance management. The most convenient option is based on the appropriate use of insecticides. The moment of insecticide use, method of use (combined or single), the frequency and duration of use need to be planned accordingly to delay the spread of vectors resistance.

\section{Competing interests}

The authors declare that they have no competing interests.

\section{Authors' contributions}

VG designed experiments, coordinated field activities, wrote and revised the paper; FRA, KB, RG, RA, RAZ, RAY, and RA participated in Laboratory activities, data collection and revised the paper; FO helped with statistical analysis and revised the paper; FTT, RA, RO helped in the study design and revised the paper; MA designed the study, supervised field activities and revised the manuscript. All authors have read and approved the content of the final version of the manuscript.

\section{Acknowledgements}

We thank the President's Malaria Initiative via the Bureau for Global Health, US Agency for International Development, and Benin National Malaria Control Programme.

\section{Author details}

${ }^{1}$ Centre de Recherche Entomologique de Cotonou (CREC), Cotonou, Benin. ${ }^{2}$ Faculté des Sciences et Techniques de I'Université d'Abomey-Calavi, Abomey-Calavi, Benin. ${ }^{3}$ Université d'Agriculture de Kétou, Kétou, Benin.

${ }^{4}$ Programme National de Lutte contre le Paludisme, Cotonou, Benin.

Received: 14 January 2015 Accepted: 29 March 2015

Published online: 12 April 2015

\section{References}

1. Curtis CF, Mnzava AE, Misra S, Rowland M. Malaria control: bednets or spraying? Summary of the presentations and the discussion. Trans R Soc Trop Med Hyg. 1999;93:460

2. Zaim M, Aitio A, Nakashima N. Safety of pyrethroid-treated mosquito nets. Med Vet Entomol. 2000;14:1-5.

3. Chavasse DC, Yap HH, World Health Organization, Division of Control of Tropical Diseases, WHO Pesticide Evaluation Scheme. Chemical methods for the control of vectors and pests of public health importance. Geneva: World Health Organization; 1997.

4. PNLP. Campagne de distribution gratuite des moustiquaires imprégnées à longue durée d'action aux ménages du Bénin. Cotonou: Ministère de la Santé; 2012. p. 11

5. PNLP-AFRICARE BENIN-CRS BENIN. Evaluation Finale Du Projet D'appui À La Lutte Contre Le Paludisme. Cotonou: Ministère de la Santé; 2011. p. 42.
6. Azondekon R, Gnanguenon V, Oke-Agbo F, Houevoessa S, Green M, Akogbeto M. A tracking tool for long-lasting insecticidal (mosquito) net intervention following a 2011 national distribution in Benin. Parasit Vectors. 2014;7:6.

7. Akogbeto M, Padonou GG, Bankole HS, Gazard DK, Gbedjissi GL. Dramatic decrease in Malaria transmission after large-scale indoor residual spraying with bendiocarb in Benin, an area of high resistance of anopheles gambiae to Pyrethroids. Am J Trop Med Hyg. 2011;85:586-93.

8. Padonou GG, Sezonlin M, Ossé R, Aizoun N, Oké-Agbo F, Oussou O, et al. Impact of three years of large scale Indoor Residual Spraying (IRS) and Insecticide Treated Nets (ITNs) interventions on insecticide resistance in Anopheles gambiae s.l. in Benin. Parasit Vectors. 2012;5:72.

9. Aïkpon R, Agossa F, Ossè R, Oussou O, Aïzoun N, Oké-Agbo F, et al. Bendiocarb resistance in Anopheles gambiae s.l. populations from Atacora department in Benin, West Africa: a threat for malaria vector control. Parasit Vectors. 2013;6:192.

10. Akogbeto M, Yakoubou S. [Resistance of malaria vectors to pyrethrins used for impregnating mosquito nets in Benin, West Africa](in French). Bull Soc Pathol Exot. 1999;92:123-30.

11. Corbel V, N'Guessan R, Brengues C, Chandre F, Djogbenou L, Martin T, et al. Multiple insecticide resistance mechanisms in Anopheles gambiae and Culex quinquefasciatus from Benin, West Africa. Acta Trop. 2007;101:207-16.

12. Djènontin A, Bio-Bangana $S$, Moiroux N, Henry M-C, Bousari $O$, Chabi J, et al. Culicidae diversity, malaria transmission and insecticide resistance alleles in malaria vectors in Ouidah-Kpomasse-Tori district from Benin (West Africa): a pre-intervention study. Parasit Vectors. 2010;3:83.

13. Djègbè I, Boussari $O$, Sidick $A$, Martin $T$, Ranson $H$, Chandre $F$, et al. Dynamics of insecticide resistance in malaria vectors in Benin: first evidence of the presence of L1014S kdr mutation in Anopheles gambiae from West Africa. Malar J. 2011;10:261.

14. Gnanguenon V, Govoetchan R, Agossa FR, Ossè R, Oke-Agbo F, Azondekon $R$, et al. Transmission patterns of Plasmodium falciparum by Anopheles gambiae in Benin. Malar J. 2014;13:444.

15. Capo-Chichi Y, Guidibi E. Monographie De La Commune De Ouidah. Cotonou: Cabinet Afrique Conseil; 2006. p. 1-44.

16. Nangbe F, Guidibi E. Monographie De La Commune D'allada. Cotonou: Cabinet Afrique Conseil; 2006. p. 1-37.

17. Gassi B, Guidibi E. Monographie De La Commune De Pobe. Cotonou: Cabinet Afrique Conseil; 2006. p. 1-46.

18. TCHEGNON P, GUIDIBI E. Monographie De La Commune D'adjohoun. Cotonou: Cabinet Afrique Conseil; 2006. p. 1-60.

19. Ahoyo Adjovi N, Guidibi E. Monographie De La Commune Kandi. Cotonou: Cabinet Afrique Conseil; 2006. p. 1-40.

20. Ahoyo Adjovi NR, Guidibi E. Monographie De La Commune De Malanville. Cotonou: Cabinet Afrique Conseil; 2006. p. 1-48.

21. CAPO-CHICHI Y, GUIDIBI E. Monographie De La Commune De Dassa. Cotonou: Cabinet Afrique Conseil; 2006. p. 1-44.

22. KORA O, GUIDIBI E. Monographie De La Commune De Parakou. Cotonou: Cabinet Afrique Conseil; 2006. p. 1-44

23. Aïkpon R, Sèzonlin M, Ossè R, Akogbéto M. Evidence of multiple mechanisms providing carbamate and organophosphate resistance in field An. gambiae population from Atacora in Benin. Parasit Vectors. 2014;7:568.

24. WHO. Test procedures for insecticide resistance monitoring in malaria vector mosquitoes. Geneva: World Health Organization; 2013.

25. Scott JA, Brogdon WG, Collins FH. Identification of single specimens of the Anopheles gambiae complex by the polymerase chain reaction. Am J Trop Med Hyg. 1993;49:520.

26. Favia G, Lanfrancotti A, Spanos L, Sidén-Kiamos I, Louis C. Molecular characterization of ribosomal DNA polymorphisms discriminating among chromosomal forms of Anopheles gambiae s.s. Insect Mol Biol. 2001;10:19-23.

27. Martinez-Torres D, Chandre F, Williamson MS, Darriet F, Berge JB, Devonshire AL, et al. Molecular characterization of pyrethroid knockdown resistance $(\mathrm{kdr})$ in the major malaria vector Anopheles gambiae s.s. Insect Mol Biol. 1998;7:179-84.

28. Weill M, Malcolm C, Chandre F, Mogensen K, Berthomieu A, Marquine M, et al. The unique mutation in ace-1 giving high insecticide resistance is easily detectable in mosquito vectors. Insect Mol Biol. 2004;13:1-7.

29. Brogdon WC, MCAllister JC. Insecticide resistance and vector control. Emerg Infect Dis. 1998:4:605-13.

30. WHO. Techniques to detect insecticide resistance mechanisms (field and laboratory manual) (archived) [http://www.who.int/malaria/publications/ atoz/who_cds_cpc_mal_98_6/en/] 
31. Aïkpon R, Sèzonlin M, Tokponon F, Okè M, Oussou O, Oké-Agbo F, et al. Good performances but short lasting efficacy of Actellic 50 EC Indoor Residual Spraying (IRS) on malaria transmission in Benin, West Africa. Parasit Vectors. 2014;7:256.

32. Sovi A, Azondékon R, Aïkpon RY, Govoétchan R, Tokponnon F, Agossa F, et al. Impact of operational effectiveness of long-lasting insecticidal nets (LLINs) on malaria transmission in pyrethroid-resistant areas. Parasit Vectors. 2013;6:319.

33. Tokponnon FT, Ogouyémi AH, Sissinto Y, Sovi A, Gnanguenon V, Cornélie S, et al. Impact of long-lasting, insecticidal nets on anaemia and prevalence of Plasmodium falciparum among children under five years in areas with highly resistant malaria vectors. Malar J. 2014;13:76.

34. Tokponnon FT, Aholoukpe B, Denon EY, Gnanguenon V, Bokossa A, N'guessan $R$, et al. Evaluation of the coverage and effective use rate of long-lasting insecticidal nets after nation-wide scale up of their distribution in Benin. Parasit Vectors. 2013;6:265.

35. Akogbeto M, Nahum A. Impact des moustiquaires imprégnées de deltaméthrine sur la transmission du paludisme dans un milieu côtier lagunaire, Bénin. Bull Soc Pathol Exot. 1996;89:291-8.

36. Aïzoun N, Aïkpon R, Akogbéto M. Evidence of increasing L1014F kdr mutation frequency in Anopheles gambiae s.l. pyrethroid resistant following a nationwide distribution of LLINs by the Beninese National Malaria Control Programme. Asian Pac J Trop Biomed. 2014;4:239-43.

37. Chouaibou MS, Chabi J, Bingham GV, Knox TB, N'Dri L, Kesse NB, et al. Increase in susceptibility to insecticides with aging of wild Anopheles gambiae mosquitoes from Côte d'Ivoire. BMC Infect Dis. 2012;12:214.

38. Diabate A, Baldet T, Chandre F, Akoobeto M, Guiguemde TR, Darriet F, et al. The role of agricultural use of insecticides in resistance to pyrethroids in Anopheles gambiae s.l. in Burkina Faso. Am J Trop Med Hyg. 2002;67:617-22.

39. Ranson H, Abdallah H, Badolo A, Guelbeogo WM, Kerah-Hinzoumbé C, Yangalbé-Kalnoné $\mathrm{E}$, et al. Insecticide resistance in Anopheles gambiae: data from the first year of a multi-country study highlight the extent of the problem. Malar J. 2009:8:299.

40. Sovi A, Djègbè I, Soumanou L, Tokponnon F, Gnanguenon V, Azondékon $R$, et al. Microdistribution of the resistance of malaria vectors to Deltamethrin in the region of Plateau (southeastern Benin) in preparation for an assessment of the impact of resistance on the effectiveness of Long Lasting Insecticidal Nets (LLINS). BMC Infect Dis. 2014;14:103.

41. Ndiath MO, Sougoufara S, Gaye A, Mazenot C, Konate L, Faye O, et al. Resistance to DDT and pyrethroids and increased kdr mutation frequency in an. Gambiae after the implementation of permethrin-treated nets in Senegal. PLoS One. 2012;7:e31943.

42. Djogbénou L, Pasteur N, Akogbéto M, Weill M, Chandre F. Insecticide resistance in the Anopheles gambiae complex in Benin: a nationwide survey. Med Vet Entomol. 2011;25:256-67.

43. Djogbénou L, Dabiré R, Diabaté A, Kengne P, Akogbéto M, Hougard JM, et al. Identification and geographic distribution of the ACE-1R mutation in the malaria vector Anopheles gambiae in south-western Burkina Faso, West Africa. Am J Trop Med Hyg. 2008;78:298.

44. Yadouleton AW, Padonou G, Asidi A, Moiroux N, Bio-Banganna S, Corbel V, et al. Insecticide resistance status in Anopheles gambiae in southern Benin. Malar J. 2010;9:83.

45. Tia E, Akogbeto M, Koffi A, Toure M, Adja AM, Moussa K, et al. Pyrethroid and DDT resistance of Anopheles gambiae s.s. (Diptera: Culicidae) in five agricultural ecosystems from Côte-d'Ivoire. Bull Soc Pathol Exot. 2006;99:278-82.

46. Nwane P, Etang J, Chouaïbou M, Toto JC, Koffi A, Mimpfoundi R, et al. Multiple insecticide resistance mechanisms in Anopheles gambiae s.l. populations from Cameroon, Central Africa. Parasit Vectors. 2013;6:41.

47. Vontas JG, Hejazi MJ, Hawkes NJ, Cosmidis N, Loukas M, Hemingway J. Resistance-associated point mutations of organophosphate insensitive acetylcholinesterase, in the olive fruit fly Bactrocera oleae. Insect Mol Biol. 2002;11:329-36

48. WHOPES. WHO recommended insecticide products for treatment of mosquito nets for malaria vector control. Geneva: World Health Organization; 2014

49. WHOPES. WHO recommended insecticides for indoor residual spraying against malaria vectors. Geneva: World Health Organization; 2015.

50. Walker K. Cost-comparison of DDT and alternative insecticides for malaria control. Med Vet Entomol. 2000;14:345-54.

51. IRAC. Prevention and management of insecticide resistance in vectors of public health importance. London: IRAC; 2011.
52. Berticat C, Boquien G, Raymond M, Chevillon C. Insecticide resistance genes induce a mating competition cost in Culex pipiens mosquitoes. Genet Res. 2002;79:41-7.

53. Corbel V, NGuess R. Distribution, Mechanisms, Impact and Management of Insecticide Resistance in Malaria Vectors: A Pragmatic Review. In: Manguin S, editor. Anopheles mosquitoes - New insights into malaria vectors, InTech. 2013.

54. WHO. Global strategic framework for integrated vector management [http:// www.who.int/malaria/publications/atoz/who_cds_cpe_pvc_2004_10/en/]

\section{Submit your next manuscript to BioMed Central and take full advantage of:}

- Convenient online submission

- Thorough peer review

- No space constraints or color figure charges

- Immediate publication on acceptance

- Inclusion in PubMed, CAS, Scopus and Google Scholar

- Research which is freely available for redistribution 